\title{
MAGEC2, an epithelial-mesenchymal transition inducer, is associated with breast cancer metastasis
}

\author{
Fan Yang $\cdot$ Xingchun Zhou $\cdot$ Xia Miao $\cdot$ \\ Tao Zhang $\cdot$ Xiaojun Hang $\cdot$ Ru Tie $\cdot$ \\ Nan Liu $\cdot$ Fei Tian $\cdot$ Fuli Wang $\cdot$ Jianlin Yuan
}

Received: 7 January 2014/ Accepted: 13 March 2014/Published online: 1 April 2014

(C) The Author(s) 2014. This article is published with open access at Springerlink.com

\begin{abstract}
MAGEC2 is a member of melanoma antigen (MAGE) family of cancer-testis antigens and associated with tumor relapse and metastasis. Here, we investigated the expression of MAGEC2 in patients with breast cancer and its clinical effects with underlying mechanisms. The expression levels of MAGEC2 were compared between 420 invasive ductal carcinoma (IDC) and 120 ductal carcinoma in situ of the breast. Correlations between MAGEC2 expression and clinico-pathologic factors or survival of patients with IDC were analyzed. In addition, MAGEC2 expression levels in tumor tissues dissected from the primary focus and matched tumor-invaded axillary lymph nodes were analyzed in 8 breast cancer patients. The functional effects of MAGEC2 overexpression were assessed in vitro using scratch assay and transwell chamber assay. MAGEC2 expression was increased in metastatic breast cancer in comparison to the non-metastatic.
\end{abstract}

Fan Yang and Xingchun Zhou are co-first authors.

F. Yang $\cdot$ F. Wang $(\bowtie) \cdot$ J. Yuan $(\bowtie)$

Department of Urology, Xijing Hospital, the Fourth Military

Medical University, Xi' an 710032, Shaanxi Province, China

e-mail: wangfuli98@163.com

J. Yuan

e-mail: Jianlinyuan2013@163.com

X. Zhou $\cdot$ X. Hang $\cdot$ R. Tie $\cdot$ N. Liu $\cdot$ F. Tian

Experimental Teaching Center of Basic Medicine, the Fourth

Military Medical University, Xi'an, Shaanxi Province, China

X. Miao

Department of Radiation Medicine, College of Preventive

Medicine, the Fourth Military Medical University, Xi' an, China

T. Zhang

Department of Hematology, Xijing Hospital, the Fourth Military

Medical University, Xi'an, China
MAGEC2 expression was significantly associated with ER negative expression $(\mathrm{P}=0.037)$, high tumor grade $(P=0.014)$ and stage $(P=0.002)$, high incidence of axillary lymph node metastasis $(P=0.013)$, and distant metastasis $(P=0.004)$. Patients with tumor with MAGEC2 positive expression have a worse prognosis and a shorter metastasis free interval. Multivariate analyses showed that MAGEC2 expression was an independent risk factor for patient overall survival and metastasis-free survival. Breast cancer cells that overexpressed MAGEC2 had stronger migratory and invasive potential than controltreated cells. Epithelial markers (E-cadherin and cytokeratin) were down-regulated in MAGEC2-overexpressing cells compared to controls, whereas mesenchymal markers (vimentin and fibronectin) were upregulated. Our results indicate that MAGEC2 has a role in breast cancer metastasis through inducing epithelial-mesenchymal transition. In addition, MAGEC2 is a novel independent poor prognostic factor in patients with IDC. Thus, targeting MAGEC2 may provide a novel therapeutic strategy for breast cancer treatment.

Keywords MAGEC2 - Breast cancer - Metastasis · Clinical outcome $\cdot$ Epithelial-to-mesenchymal transition

\section{Introduction}

Breast cancer is the leading cause of cancer mortality in females worldwide [1]. Death from breast cancer primarily results from cancer cells invading surrounding tissues and metastasizing to distal organs, such as lung, bone, liver, or brain. The epithelial-mesenchymal transition (EMT), a developmental process in which epithelial cells lose polarity and develop a mesenchymal phenotype, has been 
implicated in the initiation of cancer invasion and metastasis.

EMT is a complex multistep event, which is characterized by a loss of intercellular adhesion of E-cadherin and occludins, down-regulation of epithelial makers of cytokeratins, up-regulation of mesenchymal markers of vimentin, and fibronectin, acquisition of fibroblast-like morphology with cytoskeleton reorganization and increase in motility, invasiveness, and metastatic capabilities [2-6]. In addition, the process known as "cadherin switching" (down-regulation of E-cadherin and up-regulation of mesenchymal cadherins such as $N$-cadherin or cadherin-11) and the accumulation of $\beta$-catenin has also been associated with EMT [4]. EMT is driven by a restricted number of transcription factors that regulate the expression of numerous proteins involved in cell polarity, cell-to-cell contact, cytoskeleton structure, and extracellular matrix degradation. These transcription factors mainly include members of the three protein families Snail, Slug and Twist [7, 8]. These factors act as transcriptional repressors of E-cadherin [7,9] and modulate directly or indirectly the expression of a wide number of genes involved in cancer invasion and metastasis $[10,11]$. The EMT has been found to endow mammary epithelial cells with stem cell-like properties, including the ability to self-renew and efficiently initiate tumors $[11,12]$. Increasing evidence has shown that malignant cells in breast cancer undergo EMT to become more motile and invasive. This is particularly the case in the most lethal and aggressive subtype of triplenegative breast cancer [13, 14].

Cancer/testis antigens (CTAs) are a group of tumorassociated antigens that have normal expression in the adult testis, but aberrant expression in several cancer types, particularly advanced cancers with stem cell-like characteristics $[14,15]$. Melanoma antigen (MAGE) family genes were the first identified cancer-testis (CT) antigen [16]. MAGE expression in malignancies has been correlated with aggressive clinical course, the acquisition of resistance to chemotherapy, and poor clinical outcomes [1620]. MAGE expression has been shown to cause accelerated cell cycle progression, to increase the rate of cell migration and invasion in vitro, and to increase lung metastases in an orthotopic mouse model of human thyroid cancer [21-23]. MAGEC2 belongs to the MAGE-family of CTAs, the gene shows significant homology with the MAGEC1 gene and both genes map in close proximity to chromosome Xq27.13. MAGEC2 is solely expressed in the testis under normal circumstances but overexpressed in many malignant neoplasms. MAGEC 2 expression has been found to suppress apoptosis, increase the likelihood of metastasis and enhance the oncogenic nature of cancer cells [17, 24-28]. Data showed that MAGEC2 expressed in melanoma and prostate cancer is associated with tumor progression and poor prognosis [21, 25]. Chen et al. [29] recently determined that MAGEC2 was preferentially expressed in hormone receptor-negative and high-grade invasive ductal breast cancer [30]. However, the mechanism by which MAGEC 2 results in more aggressive tumors that are likely to metastasize remains unclear, and further investigations into the role and mechanism of MAGEC2 in breast cancer are needed.

The aim of this study was to investigate the function of MAGEC2 in breast cancer and its underlying mechanism. We first compared MAGEC2 expression between metastatic and non-metastatic breast cancer tissues and analyzed the correlation between MAGEC2 expression and clinicopathologic factors or survival of patients with IDC. We then conducted in vitro studies to overexpress MAGEC2 in breast cancer cell line to investigate the effects of MAGEC2 on the metastatic potential of cancer cells. We demonstrate that MAGEC2 is a unique activator of EMT in human breast cancer cells, which promotes breast cancer progression. It may, therefore, be a promising therapeutic target for breast cancer and a potential prognostic biomarker.

\section{Materials and methods}

\section{Patients and tissue specimens}

In total, 540 breast cancer and 23 noncancerous breast tissues were from the Tissue Bank of the Department of Pathology, Xijing Hospital, Xi' an, China. Female patients were diagnosed with breast cancer between January 2001 and December 2002. Their diagnosis was confirmed by pathologists, and comprises 120 cases of DCIS and 420 IDC of the breast. All samples were fixed by formalin and a breast cancer tissue microarray was constructed as previously described [31]. The clinico-pathologic features of all patients are summarized in Table 1. All patients had follow-up records for over 10 years. The follow-up deadline was December 2011. The overall survival (OS) was defined as the period from the first postoperative day to the final follow-up visit or death. Metastasisfree survival (MFS) was defined as the period from the first postoperative day to the date that a distant metastasis (Refers to metastasis to distant organs including bone, as well as lung, liver, and brain.) was diagnosed.

In addition, surgical specimens were collected from 8 patients with invasive ductal carcinoma who underwent modified radical mastectomy. Fresh tumors tissue from primary focus and tumor-invaded axillary lymph nodes were dissected by pathologist according to a standardized protocol. Tumors tissue was snap-frozen in liquid nitrogen and stored at $-80{ }^{\circ} \mathrm{C}$.

This study protocol was approved by the Institutional Review Board of the Fourth Military Medical University 
Table 1 Relationship of MAGEC2 expression and clinicopathologic characteristics of patients with IDC

\begin{tabular}{|c|c|c|c|}
\hline \multirow[t]{2}{*}{ Variables } & \multicolumn{3}{|c|}{ MAGEC2/CT10 expression } \\
\hline & $\begin{array}{l}\text { Negative, } n(\%) \\
(n=306)\end{array}$ & $\begin{array}{l}\text { Positive, } n(\%) \\
(n=114)\end{array}$ & $P$ value \\
\hline \multicolumn{4}{|l|}{ Age at menarche } \\
\hline$\leq 14$ (years) & $127(77.4)$ & $37(22.6)$ & 0.091 \\
\hline$>14$ (years) & $179(69.9)$ & $77(30.1)$ & \\
\hline \multicolumn{4}{|l|}{ Menopausal status } \\
\hline Premenopausal & $165(72.1)$ & $64(27.9)$ & 0.685 \\
\hline Premenopausal & $141(73.85)$ & $50(26.6)$ & \\
\hline \multicolumn{4}{|l|}{ Tumor size } \\
\hline$\leq 2 \mathrm{~cm}$ & $94(69.1)$ & $42(30.9)$ & 0.137 \\
\hline $2-5 \mathrm{~cm}$ & $115(71.0)$ & $47(29.0)$ & \\
\hline$>5 \mathrm{~cm}$ & $97(79.5)$ & $25(20.5)$ & \\
\hline \multicolumn{4}{|l|}{ Tumor grade } \\
\hline 1 & $90(78.9)$ & $24(21.1)$ & $0.014 *$ \\
\hline 2 & $120(76.4)$ & 37 (23.6) & \\
\hline 3 & $96(64.4)$ & $53(35.6)$ & \\
\hline \multicolumn{4}{|l|}{ Lymph node stage } \\
\hline 1 (Negative) & $98(78.4)$ & $27(21.6)$ & $0.013^{*}$ \\
\hline $\begin{array}{c}2(1-3 \mathrm{LN} \\
\text { involved })\end{array}$ & $136(75.6)$ & $44(24.4)$ & \\
\hline $3(>5)$ & $72(62.6)$ & $43(37.4)$ & \\
\hline \multicolumn{4}{|l|}{ Tumor stage } \\
\hline $\mathrm{I}+\mathrm{II}$ & $196(78.4)$ & $54(21.6)$ & $0.002 *$ \\
\hline $\mathrm{III}+\mathrm{VI}$ & $110(64.7)$ & $60(35.3)$ & \\
\hline \multicolumn{4}{|c|}{ Distant metastasis } \\
\hline Yes & $126(66.0)$ & $65(34.0)$ & $0.004 *$ \\
\hline No & 180 (78.6) & $49(21.4)$ & \\
\hline \multicolumn{4}{|l|}{ ER } \\
\hline Negative & $121(67.6)$ & $58(32.4)$ & $0.037 *$ \\
\hline Positive & $185(76.8)$ & $56(23.2)$ & \\
\hline \multicolumn{4}{|l|}{ PR } \\
\hline Negative & $152(75.2)$ & $50(24.8)$ & 0.289 \\
\hline Positive & 154 (70.6) & $64(29.4)$ & \\
\hline \multicolumn{4}{|l|}{ HER2 } \\
\hline Negative & $161(69.7)$ & $70(30.3)$ & 0.107 \\
\hline Positive & 145 (76.7) & $44(23.3)$ & \\
\hline
\end{tabular}

* Statistically significant $(P<0.05)$

(No. 2011039162). Tumor specimens were collected after informed consent was obtained from each patient in accordance with prior institutional guidelines (Nos. 2008039085 and 2008039085).

Immunohistochemistry

Anti-MAGEC2 monoclonal antibody (FMMU-CT10.5) [32] was kindly provided by the Department of
Immunology at the Fourth Military Medical University. MAGEC2 expression in the tissue microarray (TMA) was analyzed using the EnVision-HRP detection system (DakoCytomation Colorado Inc, Fort Collins, CO, USA) according to the manufacturer's protocol. Briefly, serial sections were cut from TMA blocks for immunohistochemical staining. The tissues were deparaffinized in xylene and rehydrated through an ethanol gradient. Antigen retrieval was performed by incubation for 2 min with Dako target retrieval solution in a pressure cooker followed by the treatment of slides with $0.3 \%$ hydrogen peroxide for $10 \mathrm{~min}$ to block endogenous peroxide activity. Samples were then incubated at $4{ }^{\circ} \mathrm{C}$ overnight with FMMUCT10.5 (1:1,000). After a further incubation with Envision reagent for $30 \mathrm{~min}$, slides were washed thoroughly with PBS and the antibody reaction was visualized using a fresh substrate solution containing DAB. The sections were counter-stained with hematoxylin. Mouse $\operatorname{IgG}$ without the primary antibody was used as the negative control.

Immunostaining scores

Two investigators (Xia Miao and Tao Zhang) separately and independently evaluated the immunohistochemical staining without knowledge of the clinical data. The results of immunohistochemical staining for MAGEC2 were semiquantitatively evaluated as described by Hideki et al. [33]. The results were evaluated using the following formula:

Immunohistochemical score $($ histoscore $)=\sum_{i=0}^{i=4} \mathrm{P}(\mathrm{i}) \times \mathrm{i}$

where staining intensity (i) was rated from 0 (negative) to 4 (strongest) on a quantitative scale (P) from 0 to $100 \%$ of positive-staining cells. The range of possible scores was from 0 to 400 .

\section{Western blotting}

Frozen tissues or cells were washed with ice-cold phosphatebuffered saline (PBS), then lysed with radioimmunoprecipitation assay lysis buffer (Beyotime, Shanghai, China) and centrifuged at $10,000 \times \mathrm{g}$. Supernatants were collected and the total protein was determined using a Bicinchoninic acid (BCA) kit (Boster, Wuhan, China). The extracted proteins (20 $\mu \mathrm{g}$ per lane) were separated on a $12 \%$ SDS-polyacrylamide gel, and transferred to nitrocellulose filters. The filters were blocked with TBST buffer $(10 \mathrm{mM}$ Tris- $\mathrm{HCl}$, pH 8.0, $0.15 \mathrm{M} \mathrm{NaCl}, 0.05 \%$ Tween 20 ) containing $5 \%$ skim milk, before being incubated with a monoclonal antibody to MAGE2/CT10 (1:1,000 dilution) overnight. This 
was followed by the addition of horseradish peroxidaselinked anti-mouse IgG and ECL visualization of the bands.

Cell lines and transfection

Breast cancer cell lines of SK-BR-3, MDA-MB-231 and MCF-7 were obtained from American Type Culture Collection (ATCC). Breast cancer cell lines of Bcap-37(ER positive) were kindly provided by the Department of Radiation Medicine at the Fourth Military Medical University. All cell lines were cultured in RPMI-1640 medium at $37{ }^{\circ} \mathrm{C}$ in $5 \% \mathrm{CO} 2$. Culture medium was supplemented with $10 \%$ fetal bovine serum, penicillin $(100 \mathrm{U} / \mathrm{ml})$, and streptomycin $(100 \mu \mathrm{g} / \mathrm{ml})$. The CMV4-MAGEC2 eukaryotic expression vector and CMV4-flag mock vector were transfected into MCF-7 cells using Fugen HD (Roche). Transfected cells were subsequently selected in the presence of $500 \mu \mathrm{g} / \mathrm{mL} \mathrm{G} 418$ (Invitrogen, Carlsbad, CA). The resistant clones were selected by trypsinization in cloning cylinders and grown separately under selective conditions.

\section{$\underline{\text { Scratch assay [34] }}$}

The cells were seeded onto 24-well plates at a density of $2 \times 10^{5}$ per well and incubated until they reached confluency. Confluent monolayers were serum-starved for $24 \mathrm{~h}$ and washed with PBS. The cell layers were then scored with a sterile $200-\mu \mathrm{L}$ pipette tip to generate one homogeneous wound. After washing with PBS, the cells were incubated with culture medium (1\% FBS) for $36 \mathrm{~h}$. Then, the images were captured by microscope at $100 \times$ magnifications (TE2000; Nikon, Tokyo, Japan). The movement distance of the cells across the wound was measured using Vision Assistant 8.6 software (National Instruments, Austin, TX).

Transwell chamber assay

The invasive ability of cells was performed in 24-well transwell chambers. The polycarbonate filters containing $8-\mu \mathrm{m}$ pores were coated on ice with $80 \mu \mathrm{L}$ of Matrigel (Sigma-Aldrich) at $5 \mathrm{mg} / \mathrm{L}$. After blocking with $1 \%$ BSA for $1 \mathrm{~h}$ at $37^{\circ} \mathrm{C}$ the cells $\left(5 \times 10^{5} / \mathrm{mL}\right)$ were suspended in serum-free culture medium, and $100 \mu \mathrm{L}$ were added to the upper compartments of a transwell chamber. In each lower chamber, $600 \mu \mathrm{L}$ of medium (5\% FBS) was added. After $12 \mathrm{~h}$ incubation, the cells from the upper compartment of the filter were removed with a cotton swab, and then the cells on the lower surface of the filter were fixed in ethanol and stained with hematoxylin-eosin. The cells that invaded through the Matrigel and reached the lower surface of the filter were quantified by counting the number of cells that migrated in 10 random microscopic fields per filter at a magnification of $200 \times$ (TE2000,Nikon).
Immunofluorescence

Cells were plated on round coverslips (Boster, Wuhan, China), and cultured in six-well plates until $\sim 80 \%$ confluency was reached. Cells were fixed in $4 \%$ paraformaldehyde for $15 \mathrm{~min}$, permeabilized with $0.1 \%$ Triton/PBS for $3 \mathrm{~min}$ at room temperature, and blocked by $5 \%$ normal goat serum for $30 \mathrm{~min}$. The cells were then incubated with primary antibodies (Boster, Wuhan, China) for $1 \mathrm{~h}$, followed by incubation with the Alexa Fluor ${ }^{\circledR} 488$ or Alexa Fluor $^{\circledR} 555$ conjugated secondary antibodies for $30 \mathrm{~min}$ at $37{ }^{\circ} \mathrm{C}$. Finally, cells on the round coverslips were photographed with a confocal laser scanning microscope (FV1000, Olympus).

\section{Statistical analysis}

SPSS version 16.0 was used for the statistical analyses. $P<0.05$ was considered significant. Correlation between MAGEC2 expression and clinico-pathological parameters was estimated using the Pearson correlation method. Parametric variables between groups were compared using Student's $\underline{t}$ test. Kaplan-Meier survival curves were calculated using tumor metastasis or death as the end points [35]. Differences in the MFS or OS rates were examined by log-rank tests. In addition, the Cox proportional hazard regression model was used to identify independent prognostic factors for MFS and OS [35].

\section{Results}

MAGEC2 expression in tumor tissue correlated with tumor metastasis

To analyze the function of MAGEC2 in breast cancer progression, we evaluated MAGEC2 protein expression in 23 noncancerous breast, 120 DCIS and 420 IDC samples. Immunostaining revealed that MAGEC2 protein was not found in noncancerous breast samples but was positive in DCIS and IDC samples. As shown in Fig. 1A, differential MAGEC2 expression between DCIS and IDC tissue could be observed: the percentage of MAGEC2 positivity in patients with DCIS was $8.33 \%(10 / 120)$ which increased to $27.14 \%(114 / 420)$ in patients with IDC. MAGEC2 protein levels were much higher in patients with IDC than DCIS. The average MAGEC2 histoscore was 65 in patients with DCIS which was increased to 175 in patients with IDC (Fig. 1B). To evaluate intraindividual difference, MAGEC2 protein expressed in tumor tissues dissected from the primary focus and matched tumor-invaded axillary lymph nodes were analyzed in 8 breast cancer patients 

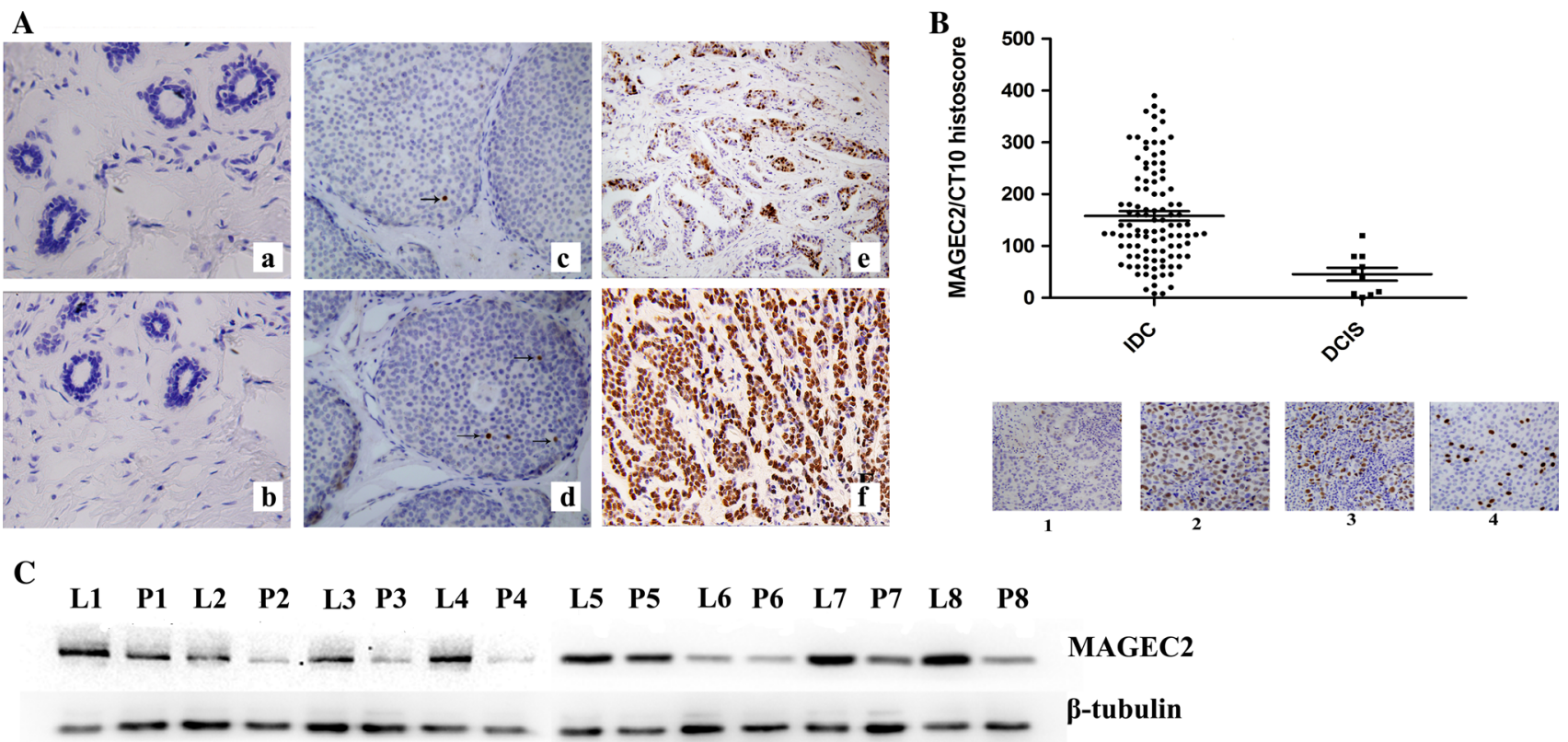

Fig. 1 Expression of MAGEC2 in metastatic and non-metastatic breast cancer tissues. A expression of MAGEC2 in noncancerous breast (a, b), DCIS (c, d) and IDC (e, f) tissues determined by immunohistochemistry. B histoscores of MAGEC2 expression in patients with DCIS and IDC (above) and representative staining intensity ranged from1-4(below). C expression of MAGEC2 in tumor tissues dissected from the primary focus and matched tumor-invaded axillary lymph nodes detected by immunoblot using $\beta$-tubulin as a loading control $(\mathrm{P}$, primary tumor. $\mathrm{L}$, the matched lymph node metastasis) by Western blot. The result verified that MAGEC2 expression was increased in metastatic lesions (Fig. 1C).

\section{MAGEC2 expression and clinico-pathologic features}

According to the expression of MAGEC2, the patients with IDC were divided into MAGEC2 positive (histoscore $>0$ ) and negative (histoscore $=0$ ) groups. Correlation analysis was then performed. The results are summarized in Table 1. There was no significant difference $(P>0.05)$ in age at menarche, menopausal status, tumor size, PR, and HER2 expression between the MAGEC2-negative group and the MAGEC2-positive group. However, MAGEC2 expression was significantly associated with ER status $(P=0.037)$, tumor stage $(P=0.002)$, Tumor grade $(P=0.014)$, lymph node stage $(P=0.013)$, and distant metastasis $(P=0.004)$. Patients with MAGEC2 positive expression were more frequently with ER negative expression, high tumor grade and stage, high incidence of axillary lymph node metastasis, and distant metastasis.

\section{Correlation between MAGEC2 expression and survival}

To examine the hypothesis that MAGEC2 may impact the survival of patients with IDC, Kaplan-Meier analysis and the COX hazard proportional model were employed to analyze survivability. To analyze a more homogeneous group of patients, Kaplan-Meier analysis stratified by MAGEC2 status was conducted in different tumor grade. As shown in Fig. 2, the positive MAGEC2 staining is significantly related to OS and MCF in both low- and highgrade tumors. Patients with positive MAGEC2 expression have a worse prognosis and a shorter metastasis free interval.

The Cox multiple variable analysis showed that MAGEC2 was an independent factor that could determine OS and MFS durations (Table 2).

Expression of MAGEC2 in breast cancer cell lines

We selected four breast cancer cell lines, SKBR-3, MDAMB-231, Bcap-37, and MCF-7, to investigate their MAGEC2 expression levels as determined by Western blot. High expression of MAGEC2 was observed in SKBR3 and MDA-MB-231, whereas Bcap-37and MCF-7 showed no expression of MAGEC2 (Fig. 3a).

MAGEC2 increases migration and invasion of breast cancer cells

To further confirm the effect of MAGEC2 on the metastasis of breast cancer cells, MCF-7 cells were stably transfected with full-length human MAGEC2 and the cell lines showing high-level expression of MAGEC2 were 
Grade I

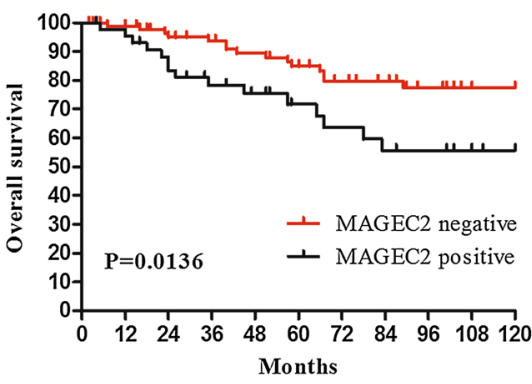

Grade I

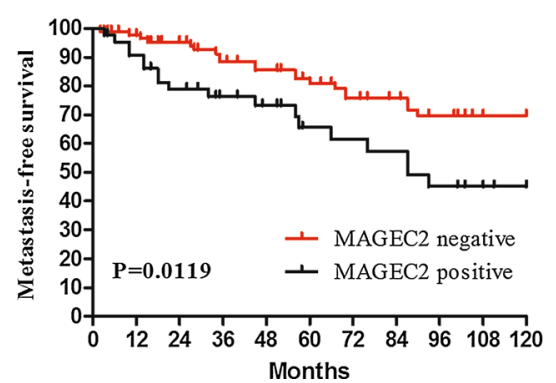

Grade II

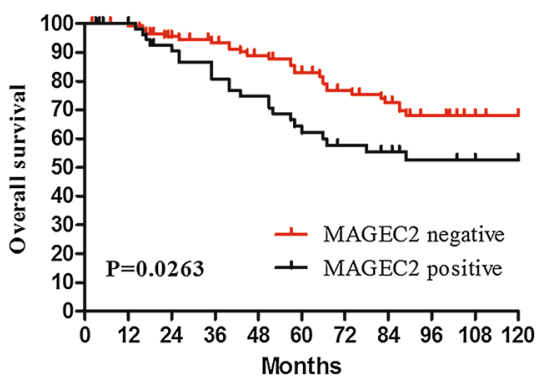

Grade II

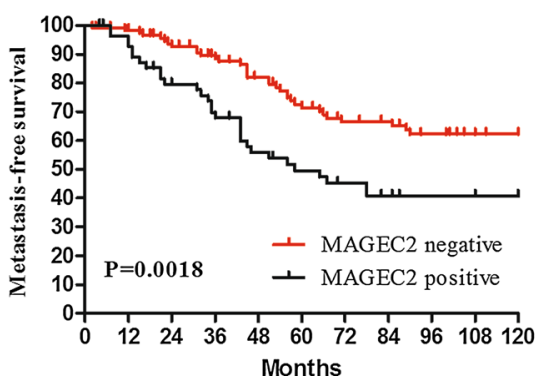

Grade III

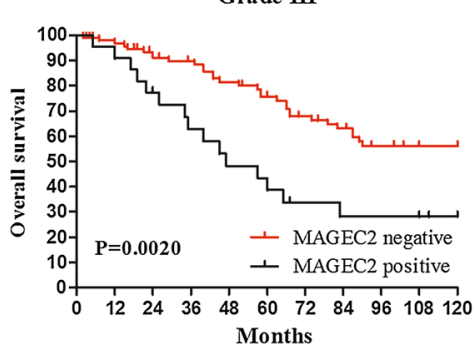

Grade III

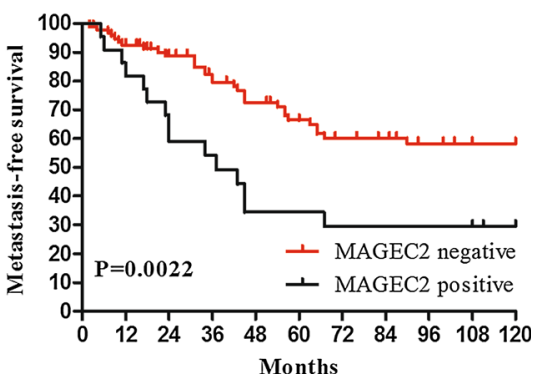

Fig. 2 Kaplan-Meier curves for OS and MFS of patients with IDC. Patients with MAGEC2 positive expression had a significantly shorter OS and DFS time in tumor grade I $(\mathbf{a}, \mathbf{b})$, grade II $(\mathbf{c}, \mathbf{d})$ and grade III $(\mathbf{e}, \mathbf{f})$

Table 2 Multivariate cox regression analysis of OS and MFS in the patients with IDC

$H R$ hazard ratio, $C I$ confidence interval

* Statistically significant $(P<0.05)$

\begin{tabular}{|c|c|c|c|c|}
\hline \multirow[t]{2}{*}{ Variable } & \multicolumn{2}{|l|}{ OS } & \multicolumn{2}{|l|}{ MFS } \\
\hline & HR $(95 \%$ CI $)$ & $P$ & HR (95\% CI) & $P$ \\
\hline Grade (3 vs 1,2$)$ & $3.12(1.54-13.26)$ & $<0.001 *$ & $6.54(1.45-14.35)$ & $<0.001 *$ \\
\hline LN Stage (2, 3 vs 1$)$ & $4.27(1.03-10.25)$ & $0.005^{*}$ & $7.13(1.85-24.32)$ & $0.015^{*}$ \\
\hline tumor size $(\geq 5 \mathrm{~cm}$ vs $<5 \mathrm{~cm})$ & $2.14(0.62-5.23)$ & 0.061 & $1.05(0.78-6.27)$ & 0.058 \\
\hline Distant metastasis (positive vs negative) & $3.36(1.46-18.10)$ & $<0.001 *$ & $6.58(2.35-34.27)$ & $<0.001 *$ \\
\hline Tumor stage (III-VI vs I-II) & $2.34(1.61-7.63)$ & $0.031 *$ & $4.65(1.06-15.42)$ & $0.032 *$ \\
\hline ER (positive vs negative) & $0.62(0.34-5.63)$ & 0.135 & $0.68(0.34-7.13)$ & 0.082 \\
\hline HER2 (positive vs negative) & $3.35(0.83-4.16)$ & 0.135 & $3.42(0.91-5.26)$ & 0.103 \\
\hline PR (positive vs negative) & $0.71(0.24-3.45)$ & 0.506 & $0.63(0.25-4.83)$ & 0.182 \\
\hline MAGEC2/CT10 (positive vs negative) & $3.07(1.47-12.01)$ & $0.003^{*}$ & $5.17(1.36-16.19)$ & $0.002 *$ \\
\hline
\end{tabular}

selected. Elevated MAGEC2 levels were confirmed by Western blot analyses (Fig. 3b). The migratory and invasive properties of cells were determined by scratch assay and transwell chamber assay. The result shows that MAGEC2-overexpressing cells displayed significantly increased migration and invasion as compared with control cells (Fig. 3c, d).

\section{Overexpression of MAGEC2 induced EMT}

Based on the association between MAGEC2 expression and the migration and invasion of cancers, and given that EMT plays a crucial role in cancer metastasis and invasion, we compared the expression of epithelial and mesenchymal markers in cancer cells using Western blotting. As shown in Fig. 4a, the epithelial markers, E-cadherin, and cytokeratin, were significantly down-regulated in MAGEC2overexpressing cells compared with the control mocktransfected cells. In contrast, the mesenchymal markers, vimentin, and fibronectin were upregulated in MAGEC2overexpressing cells. These observations were also confirmed by immunofluorescence assays (Fig. 4b).

\section{Discussion}

In this study, we are unique in demonstrating that MAGEC2 is a positive regulator of ductal breast cancer 
Fig. 3 MAGEC2 increases

migration and invasion of breast cancer cells. a expression of MAGEC2 in four breast cancer cell lines was detected by immunoblot using $\beta$-tubulin as a loading control. b MCF-7 cells were stably transfected with MAGEC2 as described in

Materials and Methods.

c Scratch assay was performed to compare the migratory capabilities of cells. d Transwell chamber assay was used to compare the invasive capabilities of cells.

*Significant difference $(P<0.05)$
A

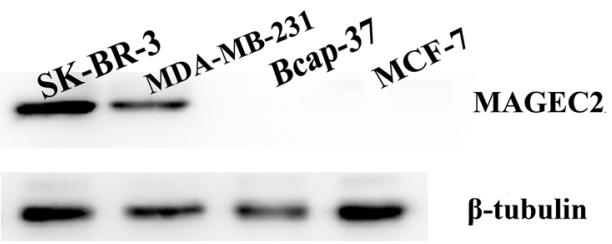

C

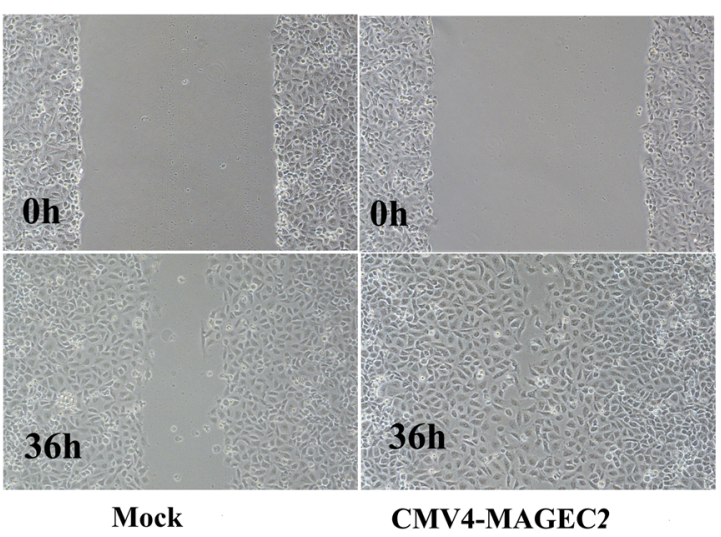

D
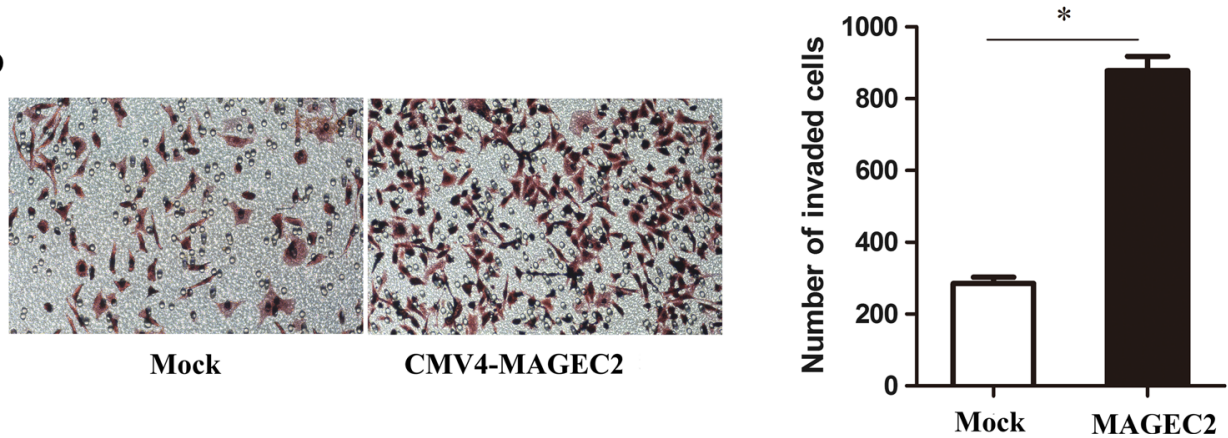

B
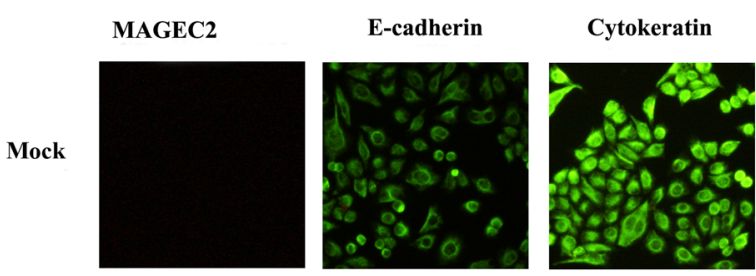

Vimentin
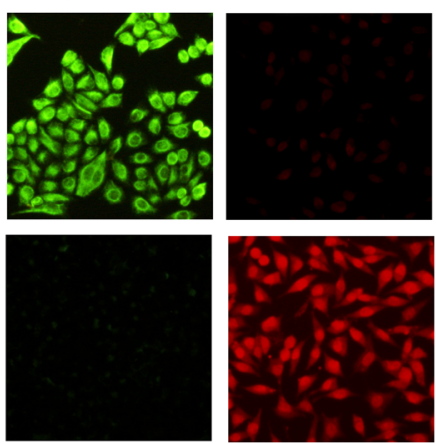
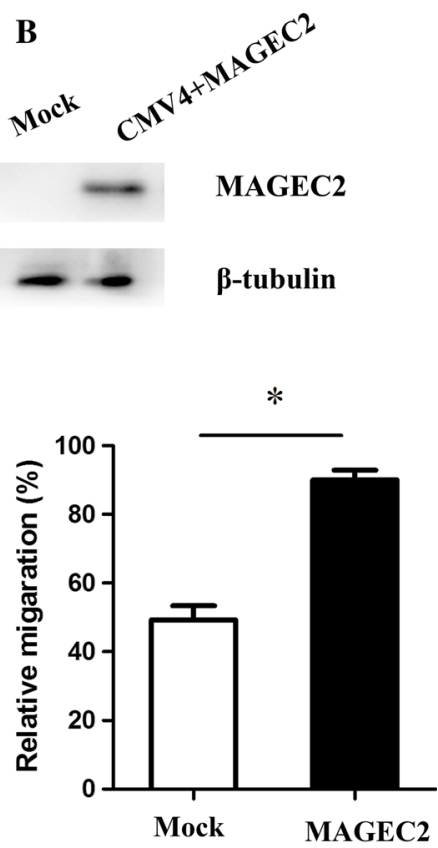

CMV4+MAGEC2
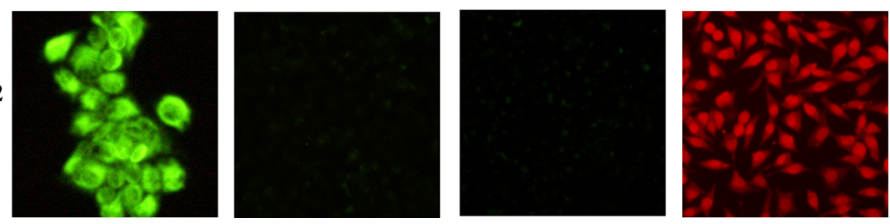

Fibronectin
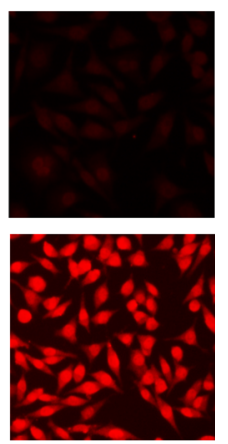

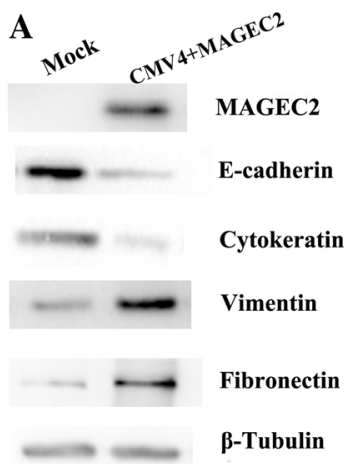

Fig. 4 MAGEC2 induces EMTs in human breast cancer cells. a expression of MAGEC2 and EMT markers analyzed by immunoblot. b expression of MAGEC2 and EMT markers analyzed by immunofluorescence

metastasis. We confirm this finding by providing the following evidence. First, MAGEC2 was more frequently and much higher expressed in the metastatic breast cancer.
Second, we identified MAGEC2 expression as an independent indicator of poor prognosis of IDC. Third, MAGEC2 overexpression enhanced the migration and 
invasion of breast cancer cells. Finally, MAGEC2 overexpression in breast cancer cells induced a mesenchymal phenotype. Collectively, these results are strong evidence that MAGEC2 plays a pivotal role in breast cancer progression.

Our studies revealed that MAGEC2 was preferentially expressed in patients with metastatic or ER negative breast cancer. we detected MAGEC2 expressed in $27.14 \%$ of patients with metastatic disease of IDC, but only in $8.33 \%$ of organ confined disease of DCIS. MAGEC2 was more frequently expressed in ER negative IDC and was negative in ER positive breast cancer cell lines of Bcap-37 and MCF7. MAGEC2 has been shown to be a reliable predictor of lymph node metastasis of melanoma, and be more frequently expressed in metastases than primary tumors [36]. Additionally, this gene is commonly expressed in both metastatic and advanced cases of prostate cancer, and is an independent predictor of recurrent disease [27]. Chen et al. [29] have demonstrated that MAGEC2 was preferentially expressed in hormone receptor-negative and high-grade IDC. Our finding corroborates previous studies and is of clinical significance. It is believed that metastatic and ERnegative breast cancers carried a much poorer prognosis than nonmetastatic and ER-positive tumors and better treatment modalities are highly desirable and continuously sought for [37]. Antibody-based immunotherapy and vaccine-mediated immunotherapy have been considered to be the hopeful approach to cure patients with metastatic and ER-negative breast cancers [38]. MAGEC2 has been shown to be able to induce specific immune responses in the autologous host. Cytotoxic $\mathrm{T}$ lymphocytes directed against MAGEC2 epitopes have been found in patients with melanoma and hepatocellular cancer [39]. MAGEC2 may be a candidate for adjuvant and palliative vaccination in the subset of patients with metastatic and ER-negative breast cancers.

Our studies elucidated the clinical significance of MAGEC2 expression in IDCs. Previous studies have shown that MAGEC2 was more frequently expressed in hormone receptor-negative and high-grade IDC [29]. However, the clinical relevance of MAGEC2 expression in IDC has not yet been investigated. In this study, we showed that MAGEC2 expression was significantly associated with tumor stage, histologic grade, lymph node metastasis, and distant metastasis and is an independent poor risk factor for predicting survival in patients with IDCs. Our results suggest that MAGEC2 might play an important role in IDC tumorigenesis and be useful as a potential prognostic biomarker for patients with IDCs.

Our studies clarified the functional role of MAGEC2 in IDC progression. Our results showed that MAGEC2 overexpression in breast cancer cells of MCF-7 can repress the epithelial phenotype, induce a mesenchymal phenotype, and dramatically increase migratory and invasive behaviors. MAGEC2 acts by binding to a well-studied transcriptional repressor, KAP1, which plays a critical role in proliferation and differentiation of both normal and tumor cells [40]. The binding of MAGEC2 to KAP1 increases the ubiquitin E3 ligase activity of KAP1 through the recruitment and/or stabilization of E3 ubiquitin-conjugating cascades, which in turn increases the ubiquitination and degradation of the tumor suppressors, p53, and ZNF382 [41]. Additionally, this process induces the expression of oncogenes, including ID1. Overexpression of ID1 can promote cadherin switching and induce EMT [4244]. KAP1 also binds to a cis-acting promoter element named fibroblast transcription site-1 (FTS-1) which exists in the promoters of genes that are known to modulate a broader EMT transcriptome, including FSP1, Twist, Snail, E-cadherin, $\beta$-catenin, vimentin, and $\alpha$-smooth muscle actin [45]. It is surprising, but intriguing that KAP-1 acts as a co-repressor but functions to activate transcription. The binding of MAGEC2 with KAP1 might explain this apparent contradiction.

More recently, the EMT program has been shown to endow normal and transformed mammary epithelial cells with stem-cell like properties, including the ability to selfrenew and efficiently initiate tumors [46]. MAGEC2 belongs to a family of CT antigens which had been implicated in stem cell differentiation pathways. MAGEC2 is normally expressed in the nuclei of spermatogonia, including spermatogonial stem cells $[47,48]$. The specific expression of MAGEC2 in tumor cells raises the question of whether it is an anomalous form of reactivated expression that confers a selective advantage to these cells, or could represent the presence of MAGEC2-expressing cells as a consequence of the clonal proliferation of a single aberrant cancer stem cell. MAGEC2 may endow those cells with stem cell properties through the induction of EMT which may have numerous implications in the progression of breast tumors.

In conclusion, we demonstrate that MAGEC2 plays a critical role in promoting breast cancer progression via the induction of EMT, which increases the motility and invasiveness of tumor cells. The utility of MAGEC2 expression as a marker of lymph node metastasis and distant metastasis, in addition to survival rates, implies that this could be a useful prognostic biomarker. Further in vitro and clinical studies will be required to understand the mechanisms by which this gene induces EMT and increases the likelihood of metastasis, and to determine whether this would be a useful therapeutic target.

Acknowledgments We thank Prof Boquan Jin for his kindly providing of the monoclonal antibody against MAGEC2 (FMMUCT10.5). This work was supported by the Natural Science Foundation of China (NO30872583, NO81072116) 
Conflict of interest The authors declare that they have no conflict of interest.

Open Access This article is distributed under the terms of the Creative Commons Attribution Noncommercial License which permits any noncommercial use, distribution, and reproduction in any medium, provided the original author(s) and the source are credited.

\section{References}

1. Jemal A, Bray F, Center MM, Ferlay J, Ward E, Forman D (2011) Global cancer statistics. CA Cancer J Clin 61(2):69-90. doi:10. 3322/caac. 20107

2. Gupta GP, Massague J (2006) Cancer metastasis: building a framework. Cell 127(4):679-695. doi:10.1016/j.cell.2006.11.001

3. Savagner P (2001) Leaving the neighborhood: molecular mechanisms involved during epithelial-mesenchymal transition. Bioessays 23(10):912-923. doi:10.1002/bies.1132

4. Thiery JP (2002) Epithelial-mesenchymal transitions in tumour progression. Nat Rev Cancer 2(6):442-454. doi:10.1038/nrc822

5. Thompson EW, Newgreen DF, Tarin D (2005) Carcinoma invasion and metastasis: a role for epithelial-mesenchymal transition? Cancer res 65(14):5991-5995. doi:10.1158/0008-5472. CAN-05-0616

6. Thiery JP, Sleeman JP (2006) Complex networks orchestrate epithelial-mesenchymal transitions. Nat Rev Mol Cell Biol 7(2):131-142. doi:10.1038/nrm1835

7. Peinado H, Olmeda D, Cano A (2007) Snail, Zeb and bHLH factors in tumour progression: an alliance against the epithelial phenotype? Nat Rev Cancer 7(6):415-428. doi:10.1038/nrc2131

8. Thiery JP, Acloque H, Huang RY, Nieto MA (2009) Epithelialmesenchymal transitions in development and disease. Cell 139(5):871-890. doi:10.1016/j.cell.2009.11.007

9. Peinado H, Portillo F, Cano A (2004) Transcriptional regulation of cadherins during development and carcinogenesis. Int $\mathrm{J}$ Dev Biol 48(5-6):365-375. doi:10.1387/ijdb.041794hp

10. De Craene B, Gilbert B, Stove C, Bruyneel E, van Roy F, Berx G (2005) The transcription factor snail induces tumor cell invasion through modulation of the epithelial cell differentiation program. Cancer Res 65(14):6237-6244. doi:10.1158/0008-5472.CAN-043545

11. Moreno-Bueno G, Cubillo E, Sarrio D, Peinado H, RodriguezPinilla SM, Villa S, Bolos V, Jorda M, Fabra A, Portillo F, Palacios J, Cano A (2006) Genetic profiling of epithelial cells expressing E-cadherin repressors reveals a distinct role for Snail, Slug, and E47 factors in epithelial-mesenchymal transition. Cancer Res 66(19):9543-9556. doi:10.1158/0008-5472.CAN-06-0479

12. Qiao B, Johnson NW, Chen X, Li R, Tao Q, Gao J (2011) Disclosure of a stem cell phenotype in an oral squamous cell carcinoma cell line induced by BMP-4 via an epithelialmesenchymal transition. Oncol Rep 26(2):455-461. doi:10.3892/ or.2011.1299

13. Coradini D, Fornili M, Ambrogi F, Boracchi P, Biganzoli E (2012) TP53 mutation, epithelial-mesenchymal transition, and stemlike features in breast cancer subtypes. J Biomed Biotechnol 2012:254085. doi:10.1155/2012/254085

14. Costa FF, Le Blanc K, Brodin B (2007) Concise review: cancer/ testis antigens, stem cells, and cancer. Stem Cells 25(3):707-711. doi:10.1634/stemcells.2006-0469

15. Cronwright G, Le Blanc K, Gotherstrom C, Darcy P, Ehnman M, Brodin B (2005) Cancer/testis antigen expression in human mesenchymal stem cells: down-regulation of SSX impairs cell migration and matrix metalloproteinase 2 expression. Cancer Res 65(6):2207-2215. doi:10.1158/0008-5472.CAN-04-1882
16. van der Bruggen $P$, Traversari C, Chomez $P$, Lurquin C, De Plaen E, Van den Eynde B, Knuth A, Boon T (1991) A gene encoding an antigen recognized by cytolytic $\mathrm{T}$ lymphocytes on a human melanoma. Science 254(5038):1643-1647

17. Kasuga C, Nakahara Y, Ueda S, Hawkins C, Taylor MD, Smith CA, Rutka JT (2008) Expression of MAGE and GAGE genes in medulloblastoma and modulation of resistance to chemotherapy Laboratory investigation. J Neurosurg Pediatr 1(4):305-313. doi:10.3171/PED/2008/1/4/305

18. Bolli M, Kocher T, Adamina M, Guller U, Dalquen P, Haas P, Mirlacher M, Gambazzi F, Harder F, Heberer M, Sauter G, Spagnoli GC (2002) Tissue microarray evaluation of Melanoma antigen E (MAGE) tumor-associated antigen expression: potential indications for specific immunotherapy and prognostic relevance in squamous cell lung carcinoma. Ann Surg 236(6):785-793. doi:10.1097/01.SLA.0000036266.09823.6C

19. Brasseur F, Rimoldi D, Lienard D, Lethe B, Carrel S, Arienti F, Suter L, Vanwijck R, Bourlond A, Humblet Y et al (1995) Expression of MAGE genes in primary and metastatic cutaneous melanoma. Int J Cancer 63(3):375-380

20. Brichard VG, Lejeune D (2007) GSK's antigen-specific cancer immunotherapy programme: pilot results leading to Phase III clinical development. Vaccine 25(Suppl 2):B61-B71. doi:10. 1016/j.vaccine.2007.06.038

21. Liu W, Cheng S, Asa SL, Ezzat S (2008) The melanoma-associated antigen A3 mediates fibronectin-controlled cancer progression and metastasis. Cancer Res 68(19):8104-8112. doi:10. 1158/0008-5472.CAN-08-2132

22. Gure AO, Chua R, Williamson B, Gonen M, Ferrera CA, Gnjatic S, Ritter G, Simpson AJ, Chen YT, Old LJ, Altorki NK (2005) Cancer-testis genes are coordinately expressed and are markers of poor outcome in non-small cell lung cancer. Clin Cancer Res 11(22):8055-8062. doi:10.1158/1078-0432.CCR-05-1203

23. Miranda EI (2010) MAGE, biological functions and potential clinical applications. Leuk Res 34(9):1121-1122. doi:10.1016/j. leukres.2010.03.045

24. Gure AO, Stockert E, Arden KC, Boyer AD, Viars CS, Scanlan MJ, Old LJ, Chen YT (2000) CT10: a new cancer-testis (CT) antigen homologous to CT7 and the MAGE family, identified by representational-difference analysis. Int J Cancer 85(5):726-732

25. Zhou X, Yang F, Zhang T, Zhuang R, Sun Y, Fang L, Zhang C, Ma Y, Huang G, Ma F, Song C, Jin B (2013) Heterogeneous expression of CT10, CT45 and GAGE7 antigens and their prognostic significance in human breast carcinoma. Jpn J Clin Oncol 43(3):243-250. doi:10.1093/jjco/hys236

26. Bode PK, Barghorn A, Fritzsche FR, Riener MO, Kristiansen G, Knuth A, Moch H (2011) MAGEC2 is a sensitive and novel marker for seminoma: a tissue microarray analysis of 325 testicular germ cell tumors. Mod Pathol 24(6):829-835

27. von Boehmer L, Keller L, Mortezavi A, Provenzano M, Sais G, Hermanns T, Sulser T, Jungbluth AA, Old LJ, Kristiansen G, van den Broek M, Moch H, Knuth A, Wild PJ (2011) MAGE-C2/ CT10 protein expression is an independent predictor of recurrence in prostate cancer. PLoS One 6(7):e21366. doi:10.1371/ journal.pone.0021366

28. Pabst C, Zustin J, Jacobsen F, Luetkens T, Kroger N, Schilling G, Bokemeyer C, Sauter G, Atanackovic D, Marx A (2010) Expression and prognostic relevance of MAGE-C1/CT7 and MAGE-C2/CT10 in osteolytic lesions of patients with multiple myeloma. Exp Mol Pathol 89(2):175-181. doi:10.1016/j.yexmp. 2010.06.011

29. Chen YT, Ross DS, Chiu R, Zhou XK, Chen YY, Lee P, Hoda SA, Simpson AJ, Old LJ, Caballero O, Neville AM (2011) Multiple cancer/testis antigens are preferentially expressed in hormone-receptor negative and high-grade breast cancers. PLoS One 6(3):e17876. doi:10.1371/journal.pone.0017876 
30. Adams S, Greeder L, Reich E, Shao Y, Fosina D, Hanson N, Tassello J, Singh B, Spagnoli GC, Demaria S, Jungbluth AA (2011) Expression of cancer testis antigens in human BRCAassociated breast cancers: potential targets for immunoprevention? Cancer Immunol Immunother 60(7):999-1007. doi:10.1007/ s00262-011-1005-7

31. Kononen J, Bubendorf L, Kallioniemi A, Barlund M, Schraml P, Leighton S, Torhorst J, Mihatsch MJ, Sauter G, Kallioniemi OP (1998) Tissue microarrays for high-throughput molecular profiling of tumor specimens. Nat Med 4(7):844-847

32. Zhuang R, Zhu Y, Fang L, Liu XS, Tian Y, Chen LH, Ouyang WM, Xu XG, Jian JL, Gure AO, Fortunato S, Ritter G, Old LJ, Simpson AJ, Chen YT, Jin B, Jungbluth AA (2006) Generation of monoclonal antibodies to cancer/testis (CT) antigen CT10/ MAGE-C2. Cancer immun 6:7

33. Sakaguchi H, Fujimoto J, Hong BL, Tamaya T (2007) Clinical implications of osteopontin in metastatic lesions of uterine cervical cancers. Cancer Lett 247(1):98-102. doi:10.1016/j.canlet. 2006.03.026

34. Zhou YC, Liu JY, Li J, Zhang J, Xu YQ, Zhang HW, Qiu LB, Ding GR, Su XM, Mei S, Guo GZ (2011) Ionizing radiation promotes migration and invasion of cancer cells through transforming growth factor-beta-mediated epithelial-mesenchymal transition. Int J Radiat Oncol Biol Phys 81(5):1530-1537. doi:10. 1016/j.ijrobp.2011.06.1956

35. Tang HR, Luo XQ, Xu G, Wang Y, Feng ZJ, Xu H, Shi YW, Zhang Q, Wu LG, Xue CQ, Wang CW, Wu CY (2012) High mobility group-box 3 overexpression is associated with poor prognosis of resected gastric adenocarcinoma. World J Gastroenterol 18(48):7319-7326. doi:10.3748/wjg.v18.i48.7319

36. Curioni-Fontecedro A, Nuber N, Mihic-Probst D, Seifert B, Soldini D, Dummer R, Knuth A, van den Broek M, Moch H (2011) Expression of MAGE-C1/CT7 and MAGE-C2/CT10 predicts lymph node metastasis in melanoma patients. PLoS One 6(6):e21418. doi:10.1371/journal.pone.0021418

37. Dunnwald LK, Rossing MA, Li CI (2007) Hormone receptor status, tumor characteristics, and prognosis: a prospective cohort of breast cancer patients. Breast Cancer Res 9(1):R6. doi:10. $1186 / \mathrm{bcr} 1639$

38. Germeau C, Ma W, Schiavetti F, Lurquin C, Henry E, Vigneron N, Brasseur F, Lethe B, De Plaen E, Velu T, Boon T, Coulie PG (2005) High frequency of antitumor $\mathrm{T}$ cells in the blood of melanoma patients before and after vaccination with tumor antigens. J Exp Med 201(2):241-248. doi:10.1084/jem.20041379
39. Straetemans T, van Brakel M, van Steenbergen S, Broertjes M, Drexhage J, Hegmans J, Lambrecht BN, Lamers C, van Der Bruggen P, Coulie PG, Debets R (2012) TCR gene transfer: MAGE-C2/HLA-A2 and MAGE-A3/HLA-DP4 epitopes as melanoma-specific immune targets. Clin Dev Immunol 2012:586314. doi: $10.1155 / 2012 / 586314$

40. Xiao TZ, Bhatia N, Urrutia R, Lomberk GA, Simpson A, Longley BJ (2011) MAGE I transcription factors regulate KAP1 and KRAB domain zinc finger transcription factor mediated gene repression. PLoS One 6(8):e23747. doi:10.1371/journal.pone. 0023747

41. Yang B, O’Herrin SM, Wu J, Reagan-Shaw S, Ma Y, Bhat KM, Gravekamp C, Setaluri V, Peters N, Hoffmann FM, Peng H, Ivanov AV, Simpson AJ, Longley BJ (2007) MAGE-A, mMage-b, and MAGE-C proteins form complexes with KAP1 and suppress p53-dependent apoptosis in MAGE-positive cell lines. Cancer Res 67(20):9954-9962. doi:10.1158/0008-5472.CAN-07-1478

42. Cheung PY, Yip YL, Tsao SW, Ching YP, Cheung AL (2011) Id1 induces cell invasiveness in immortalized epithelial cells by regulating cadherin switching and Rho GTPases. J Cell Biochem 112(1):157-168. doi:10.1002/jcb.22911

43. Cubillo E, Diaz-Lopez A, Cuevas EP, Moreno-Bueno G, Peinado H, Montes A, Santos V, Portillo F, Cano A (2013) E47 and Id1 interplay in epithelial-mesenchymal transition. PLoS One 8(3):e59948. doi:10.1371/journal.pone.0059948

44. Tobin NP, Sims AH, Lundgren KL, Lehn S, Landberg G (2011) Cyclin D1, Id1 and EMT in breast cancer. BMC Cancer 11:417. doi:10.1186/1471-2407-11-417

45. Venkov CD, Link AJ, Jennings JL, Plieth D, Inoue T, Nagai K, Xu C, Dimitrova YN, Rauscher FJ, Neilson EG (2007) A proximal activator of transcription in epithelial-mesenchymal transition. J Clin Investig 117(2):482-491. doi:10.1172/JCI29544

46. Mani SA, Guo W, Liao MJ, Eaton EN, Ayyanan A, Zhou AY, Brooks M, Reinhard F, Zhang CC, Shipitsin M, Campbell LL, Polyak K, Brisken C, Yang J, Weinberg RA (2008) The epithelial-mesenchymal transition generates cells with properties of stem cells. Cell 133(4):704-715. doi:10.1016/j.cell.2008.03.027

47. Ohman Forslund K, Nordqvist K (2001) The melanoma antigen genes-any clues to their functions in normal tissues? Exp Cell Res 265(2):185-194. doi:10.1006/excr.2001.5173

48. Chen YT, Chiu R, Lee P, Beneck D, Jin B, Old LJ (2011) Chromosome $\mathrm{X}$-encoded cancer/testis antigens show distinctive expression patterns in developing gonads and in testicular seminoma. Hum Reprod 26(12):3232-3243. doi:10.1093/humrep/der330 